\title{
Nuevas interacciones entre universidad, sociedad y territorio a través de una propuesta para una industria educacional avanzada. The Potteries
} Thinkbelt

\author{
New interactions between university, society and territory through \\ a proposal for an advanced educational industry. The Potteries \\ Thinkbelt
}

\author{
Luisa Alarcón González* y Francisco Montero-Fernández** \\ Fecha de recepción: 29-04-2017 - Fecha de aceptación: 16-09-2017 \\ Hábitat y Sociedad (ISSN 2173-125X), n. ${ }^{\circ}$ 10, noviembre de 2017, pp. 203-222. \\ http://dx.doi.org/10.12795/HabitatySociedad.2017.i10.12
}

\section{Abstract}

The current Spanish reality shows dysfunctions between university, society and territory, being necessary the realization of multidisciplinary approaches for its solution that integrate in a more efficient way these concepts. The analysis of a proposal like The Potteries Thinkbelt, with a clearly innovative content in these fields, serves to see how in the 1960s actions were proposed that combined the improvement of a place in decadence through a new system of higher studies. Cedric Price uses the architectural project as a criticism of the society in which he lives, realizing a new university system that serves as a catalyst to transform a decaying territory, plunged into a deep economic crisis, into a new place full of activity and life.

This project of a new advanced educational industry was not executed, but its innovative interpretation of reality has the capacity to survive its time, to remain in force today and to promote in our minds the development of new ideas of occupation of the territory, to generate new Habitats or to develop new learning systems, leading us to imagine new places where their intrinsic conditions will be revalued with the introduction of a new educational-productive structure.

\section{Key words}

University, Price, Industrial landscape, Mobility, Sustainability

\section{Resumen}

La realidad española actual muestra disfunciones en las relaciones universidad, sociedad y territorio, siendo necesaria la realización de planteamientos multidisciplinares para su solución que integren de manera más eficiente estos conceptos. El análisis de una propuesta como The Potteries Thinkbelt, de contenido claramente innovador en estos campos, nos sirve para ver cómo en la década de los sesenta se plantearon actuaciones que aunaban la mejora de un lugar en decadencia, a través de un nuevo sistema de estudios superiores. Cedric Price utiliza el proyecto arquitectónico como crítica de la sociedad en la que vive, realizando de manera autónoma un nuevo sistema universitario que sirve de catalizador para transformar un territorio decadente, sumido en una profunda crisis económica, en un nuevo lugar lleno de actividad y vida.

Este proyecto de una nueva industria educacional avanzada no fue ejecutado, pero su innovadora interpretación de la realidad tiene la capacidad de sobrevivir a su época, permanecer vigente hoy día y promover en nuestra mente el desarrollo de nuevas ideas de ocupación del territorio, de generar nuevos hábitats o de desarrollar nuevos sistemas de aprendizaje, llevándonos a imaginar nuevos lugares donde sus condiciones intrínsecas se revalorizarán con la introducción de una nueva estructura educativa-productiva.

\section{Palabras clave}

Universidad; Price; Paisaje industrial; Movilidad, Sostenibilidad

\footnotetext{
* Arquitecta. Profesora asociada. Departamento de Proyectos Arquitectónicos. Universidad de Sevilla. Avenida Reina Mercedes, n. ${ }^{\circ}$ 2, 41012 Sevilla. C.e.: lalarcon@us.es.

** Arquitecto. Profesor titular. Departamento de Proyectos Arquitectónicos. C.e.: fmontero@us.es.
} 


\section{Introducción}

El 2 de junio de 1966, Cedric Price publica en la revista New Society ${ }^{1}$ un proyecto denominado The Potteries Thinkbelt, conocido también por su abreviatura PTb. Su interés es tan grande que cuatro meses más tarde se publica con el título "Life-conditioning. The potteries thinkbelt: a plan for an advanced educational industry in North Staffordshire in Architectural design" (Price, 1966). Realmente, no nos encontramos frente a un proyecto arquitectónico al uso, sino frente a un innovador trabajo de investigación que Price realiza por propia voluntad, sin encargo ni cliente, para dar solución a una serie de problemas que él ha detectado en la sociedad inglesa de la época, en el sistema universitario existente y en el territorio donde habita. Para Stephen Mullin, el comienzo de PTb es una conversación en 1964 entre Price y Lord Kennet, ministro de Educación del Gobierno británico en esos momentos:

Price said: "Look, you are doing this all wrong — you are just putting up a few monuments to a medieval sense of learning. Why don't you really think about what education is about, what learning is about? How people access it?" And Kennet replied "If you are so clever, why don't you do it?" So Cedric said: "I bloody well will, then" (Hardinghan y Rattenbury, 2007, p. 103).

La respuesta de Price llega dos años más tarde a través de un plan concreto, un proyecto realizado para un lugar específico (North Staffordshire) y perfectamente datado con planos, fotomontajes, textos y números. En él plantea la construcción de un nuevo campus de enseñanza superior e investigación de 2800 hectáreas para 22000 alumnos, extendido por la región alfarera de North Staffordshire, con el que busca resolver dos de las crisis más importantes a las que se enfrentaba Gran Bretaña a mediados de los años sesenta, la industrial y la universitaria, introduciendo para ello conceptos tan novedosos como la recuperación de paisajes industriales abandonados o la reutilización de los recursos prexistentes, elementos que muestran una conciencia medioambiental pionera en ese momento.

Estudiar este proyecto arquitectónico nos va a proporcionar una visión novedosa de las interacciones que pueden producirse entre educación y sociedad y cómo esta puede servir para una transformación positiva de la misma. El arquitecto Cedric Price es un investigador que busca adaptar su disciplina, la arquitectura, a los cambios que se están produciendo en la sociedad en la que habita, la Inglaterra de la segunda mitad del siglo xx. Sus propuestas son tan innovadoras en muchos casos que, incluso hoy día, en las primeras décadas del siglo XXI, nos resultan actuales y provocadoras.

En el ejemplo que se analiza, la arquitectura no es tratada como un objeto que se impone a un territorio con un fin económico-comercial, sino que es el soporte de un nuevo sistema de enseñanza que pretende acercarse a la sociedad y proporcionarle herramientas para su desarrollo, de una forma armónica con el paisaje donde esta relación se va a producir. Este modo de actuar nos debe servir de estímulo en los desarrollos territoriales actuales y su conocimiento puede acercarnos a políticas educativas y sociales más acordes con las problemáticas actuales, de ahí el interés de este estudio y de su difusión.

1 New society era una revista semanal de investigación social y cultural, publicada en el Reino Unido entre 1962 y 1988, donde se abordaban temas sociológicos, antropológicos, de geografía humana, educación o historia, entre otros. 


\section{El contexto histórico de la década de los sesenta: elementos claves para un pensamiento propositivo}

La segunda guerra mundial trae también aparejada, junto a las destrucciones y el horror, los síntomas de una incipiente globalización que se va incrementando en la posguerra. Tanto los países que se han apoyado como los que se han enfrentado en la contienda bélica comienzan a funcionar económicamente de forma conjunta, ayudándose en la reconstrucción. En los años de conflicto han visto que el mundo era pequeño, que se podía recorrer fácilmente y que lo que sucedía a miles de kilómetros les acababa afectando de una forma u otra. El desarrollo de los medios de transporte y las comunicaciones habían acercado tanto a las poblaciones que se comienza a estructurar un mapa de funcionamiento conjunto del planeta. Una de las consecuencias de este nuevo mundo global y sus importantes desarrollos técnicos son los cambios en la industria y la producción. La facilidad del transporte permite una desvinculación de las áreas productoras de las consumidoras, también de las fuentes de materias primas y energía, por lo que el incremento del coste de la mano de obra y de los requerimientos sociales en los países tradicionalmente industrializados conduce a su relocalización en otros lugares más favorables económicamente y la consiguiente transformación de las áreas donde se situaban. ${ }^{2}$ Gran Bretaña, el país donde comenzó la revolución industrial, fue uno de los más afectados, produciéndose en su territorio una importante transformación. La contaminación y el hacinamiento humano que caracterizó a la Inglaterra del siglo XIX y que tan duramente describió Dickens en sus libros desaparecen de estos lugares, generándose en cambio nuevos pasajes de ruinas industriales, de grandes áreas transformadas por el hombre, artificializadas, pero casi deshabitadas y en estado de abandono.

A esta crisis industrial se suma la crisis en la enseñanza universitaria británica, donde la falta de inquietud y promoción en la investigación y el desarrollo de las nuevas tecnologías produjo entre los años 59 y 60 una fuga de cerebros a universidades y compañías estadounidenses. ${ }^{3} \mathrm{El}$ Ptb Price aúna esos dos estamentos en decadencia, a los que se siente fuertemente vinculado, a la universidad desde su actividad como profesor en la Architectural Association de Londres y a la industria por tradición familiar, como descendiente de industriales. ${ }^{4} \mathrm{Su}$ reflexión busca cambiar esta situación proponiendo una reactivación de las áreas industriales decadentes mediante la implantación de una nueva "industria de enseñanza superior" dedicada principalmente al estudio y la investigación de la ciencia y la tecnología, a la que no denomina universidad para remarcar las diferencias en el tipo de enseñanza que cree que se tiene que desarrollar, que debe estar muy alejada de la impartida hasta esos momentos por las elitistas universidades inglesas.

Posiblemente Price se inspirara para la concepción de PTb en la Open University, ${ }^{5}$ concebida en estos años por el sociólogo Michael Young para facilitar el acceso a los estudios superiores de más cantidad de población. El sistema se basaba en la creciente difusión que estaban teniendo la televisión y la radio a finales de los cincuenta y principios de los sesenta y los utilizaba, junto con el correo, como vehículos para transmitir el conocimiento, como una nueva forma de aprendizaje. Otra de las aportaciones de Price a la nueva industria de enseñanza es la consideración de que el estudio y la investigación son trabajos y como tales deben ser remunerados, entiende que un científico o un investigador en su período de formación hacen una aportación a la socie-
2 "2/3 de las fábricas británicas pueden producir con éxito en cualquier lugar del país, a raíz de la continuidad urbana e industrial [...]. Estos hechos demuestran una tendencia a la homogeneización del espacio desde el punto de vista de las condiciones naturales requeridas para la actividad económica. [...] Cada vez más, desde el punto de vista estrictamente técnico, el espacio será indiferenciado para la actividad. Es una manifestación concreta del paso de un medio natural a un medio técnico del que hablaba Georges Friedmann en otro contexto" (Castell, 1974, pp. 161-162).

3 "Las universidades inglesas obstaculizaban el desarrollo de las nuevas tecnologías al privilegiar la enseñanza superior como coto privado para el aprendizaje social, ignorando todo proceso y aplicación práctica. Esta situación condujo a la desastrosa fuga de cerebros de los años 59 y 60 (conocida como brain drain), cuando los mejores y más brillantes científicos e ingenieros británicos huyeron en masa a universidades y compañías estadounidenses" (Mathews, 2001, p. 19).

4 Los tatarabuelos de Cedric Price (Josiah Wedgewood y Enioch Wood) abren fábricas de porcelana a principios del siglo XVIII.

5 El departamento de Educación y Ciencia (DES), en 1964, con Jennie Lee como ministra de Cultura, desarrolló, con la BBC, lo que ha llegado a ser la Open University, una institución de educación superior con facultad para conceder premios $[\ldots]$, accediendo a través de los medios de comunicación, como la televisión, la radio o el correo (Hardinghan y Rattenbury, 2007, p. 65). 


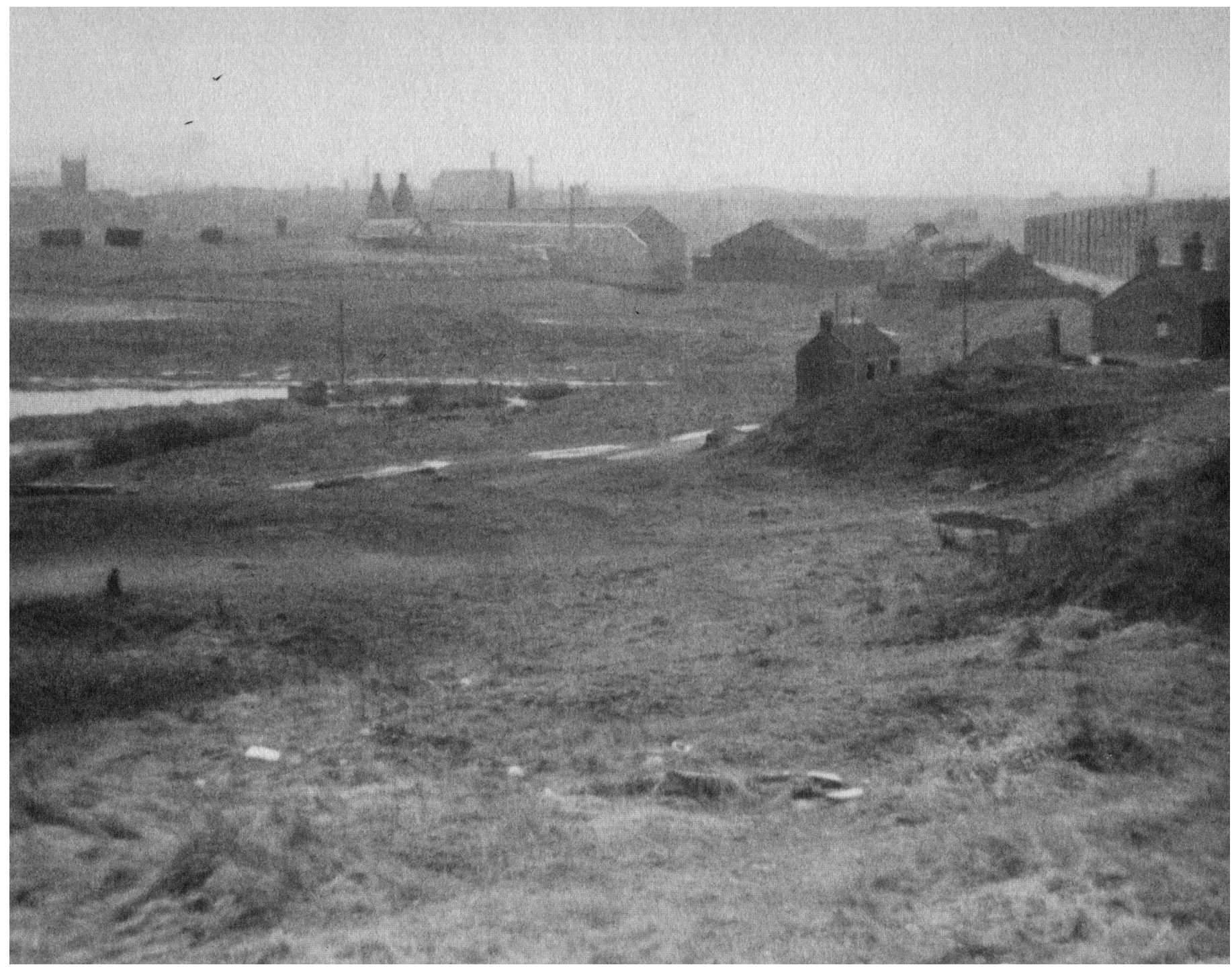

Figura 1. El paisaje de las alfarerías de North Staffordshire en 1963. Fuente: Hardingham, S. y Rattenbury, K. (eds.) (2007). Potteries Thinkbelt, Cedric Price, Supercrit\# 1. Abingdon: Routledge.

6 Los tatarabuelos de Cedric Price abren sus fábricas de porcelana en la región alfarera de North Staffordshire. La madre de Price es descendiente directa de Enioch Wood y Price nace y crece en Stone, ciudad perteneciente a esta región inglesa.

7 Era centro de los avances tecnológicos, allí Joseph Priestly realizó sus primeros experimentos de termodinámica y James Watt probó sus primeros motores a vapor. La primera máquina de vapor de Inglaterra (la Rocket de George Stephenson) transportaba materiales a y desde la Potteries, a mediados del siglo XIX la región contaba con una pujante red ferroviaria que serpenteaba por la región conectando ciudades y fábricas (Mathews, 2001, p. 19) dad equivalente a la realizada por otras profesiones en las que sí existe una contraprestación económica, por lo que esta desigualdad debe ser borrada asignándosele un sueldo a los estudiantes o trabajadores de la "industria de enseñanza".

Price elige para experimentar sus ideas un lugar que le es cercano en lo personal, ${ }^{6}$ y que por tanto conoce bien, pero que también reúne las condiciones ideales para su investigación. Se trata de un área que ha sufrido todos los procesos de la industrialización. Durante 250 años las alfarerías de North Staffordshire fueron, y aún son, el centro de la industria cerámica inglesa, desde el inicio de la producción industrial en el siglo XVIII hasta la sociedad posindustrial actual. Comienzan como pequeños negocios familiares y a mediados del siglo XIX ya se habían transformado en grandes industrias, convirtiéndose la zona en un centro de innovación donde se aprovechaban y probaban los más novedosos avances tecnológicos de la época, ${ }^{7}$ como ejemplo de ello encontramos la rápida introducción del ferrocarril, en 1848, y su expansión. A mediados del siglo xix la región contaba con una importante red ferroviaria que conectaba las fábricas a distintas ciudades. Su desarrollo industrial se mantiene como en el conjunto de la industria británica hasta la segunda guerra mundial, después de esta empezó a debilitarse al no poder competir con Estados Unidos, Alemania o Japón. Así, las Potteries de North Staffordshire fueron decayendo, quedando la zona convertida en un yermo territorio industrial de fábricas en ruinas y má- 
quinas herrumbrosas. Ante esta situación, Cedric Price propone un novedoso entendimiento del paisaje al que se enfrenta y que vemos descrito en sus propias palabras:

Un lugar árido y sucio, toscos terrenos industriales. Gran parte de las fábricas han desaparecido y la tierra está agotada, pero no es un páramo deshabitado, todavía mucha gente vive allí. En estas cien millas cuadradas que ocupa el Thinkbelt hay muy pocos árboles, muchos pozos, muchos viejos almacenes y muchas vías de tren en desuso. ${ }^{8}$

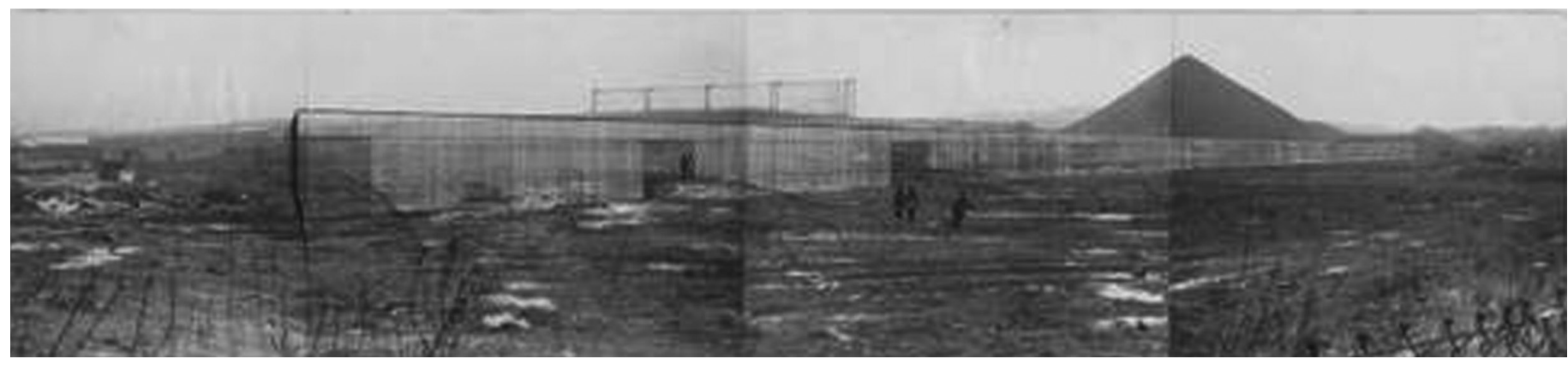

En la propuesta los desechos industriales heredados no son rechazados, sino que son valorados y asumidos como una parte más del territorio. Él no busca como los románticos decimonónicos la vuelta a una naturaleza perdida y añorada, sino que parte del estado en que se encuentra el paisaje en ese momento concreto, con su propia escala de belleza, igual que un par de años más tarde hace Robert Smithson al observar la transformación industrial de la ciudad de Passaic, a la que ve como una nueva ciudad monumental. ${ }^{9}$ Ambos se enfrentan a un paisaje que les ha sido propio, donde han nacido y pasado su niñez, y que el tiempo y el desarrollo económico han cambiado profundamente. La novedad es que frente al rechazo inicial que se podría imaginar, existe una valoración propositiva de este nuevo paisaje, si Smithson lo fotografia y describe, catalogando de monumentos los elementos singulares que son producto de la industrialización y que se encuentra en su paseo por Passaic, Price nos ofrece una nueva imagen híbrida del lugar a través de sus collages, en los que la arquitectura propuesta, de imagen claramente tecnológica, convive con total naturalidad con un paisaje abandonado de terrenos baldíos y canteras.

Ante estos nuevos lugares industriales desafectados surge una nueva visión posindustrial. Para determinados artistas el paisaje alterado y artificializado por el hombre ya no produce el rechazo que provocaba desde el inicio de la revolución industrial, sino que este paisaje no natural heredado se asume como propio, como el territorio donde se va a desenvolver a partir de estos momentos la vida humana, viendo en él cualidades propias del arte. La naturaleza idílica o salvaje ha ido desapareciendo, arrinconada por el avance imparable de la civilización, ya solo existe encerrada dentro de los parques naturales creados para su protección, y nuestro paisaje cotidiano es un mundo antropizado, lleno de infraestructuras, edificaciones, ruinas y desechos.

Estos conceptos de asunción de lo existente también se reflejan en una revalorización de las construcciones populares o las ciudades tradicionales, que mezclados con las críticas por parte de los arquitectos que forman el Team $10^{10}$ a la segregación de funciones urbanas propuesta en la Carta de Atenas, proporciona un nuevo punto de reflexión sobre
Figura 2. Collage de Potteries Thinkbelt. Longton: vista de las viviendas batería con viviendas crate y capsule a lo lejos. Fuente: Hardingham, S. y Rattenbury, K. (eds.) (2007). Potteries Thinkbelt, Cedric Price, Supercrit\# 1. Abingdon: Routledge.

8 Price, Cedric: “Transcripción de la conferencia dictada el 20 de diciembre de 2000 con motivo de la inauguración de la exposición "PTb: Caducidad, Educación y Energía” (Herreros, 2001, p. 34).

9 En septiembre de 1967 Robert Smithson realiza un viaje a Passaic, su ciudad natal, un suburbio de Nueva Jersey, un territorio en plena transformación, tras recorrer diversas zonas de la ciudad y su entorno, y calificar lo que va viendo de monumentos, él se pregunta: ¿ha sustituido Passaic a Roma como la ciudad eterna?, convirtiendo a esa área degradada por la industria en el máximo exponente de ciudad monumental (Smithson, 2006, p. 26). 10 El Team 10 es un grupo formado por los arquitectos J.B. Bakema, Aldo Van Eyck, G. Candilis, S. Woods, A \& P Smithson, John Voelcker, J. Soltan, Gier Grung, Ralph Erskine y J. Coderch en 1960. 


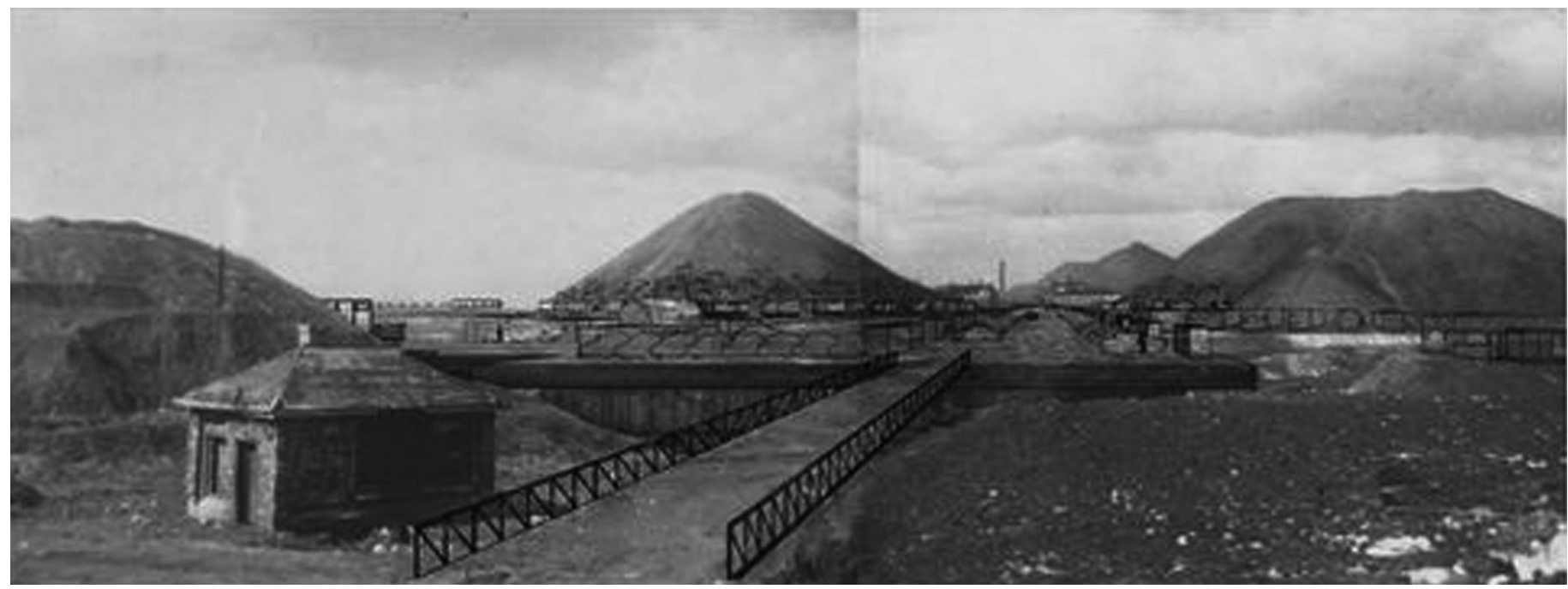

Figura 3. Collage de Potteries Thinkbelt. Hanley: viviendas batería, sprawly capsule. Fuente: Hardingham, S. y Rattenbury, K. (eds.) (2007). Potteries Thinkbelt, Cedric Price, Supercrit\# 1. Abingdon: Routledge.

Figuras 4. Golden Lane, vista general de la propuesta sobre las ruinas de Coventry. Alison \& Peter Smithson, 1952. Fuente: Vidotto, M. (1997). Alison + Peter Smithson. Obras y proyectos. Barcelona: Gustavo Gili. la ciudad y la ocupación del territorio que invalida las teorías urbanas basadas estrictamente en los principios funcionalistas. Lo existente no se borra, ni física ni mentalmente, para obtener un nítido y blanco papel para construir desde cero un nuevo mundo moderno, sino que la arquitectura se superpone al territorio que nos encontramos asumiendo su presente, su estado real, y no una idealización subjetiva del mismo. Así, el collage del prototipo de viviendas para el concurso Golden Lane de Alison y Peter Smithson de 1952 muestra la edificación sobrevolando las ruinas del centro de Coventry, producidas por los bombardeos alemanes de la segunda guerra mundial sobre Londres. El cambio de paradigma es claro, las ruinas ya no son sustituidas por el parque verde, continuo e ideal que pone fondo a las perspectivas de Le Corbu-

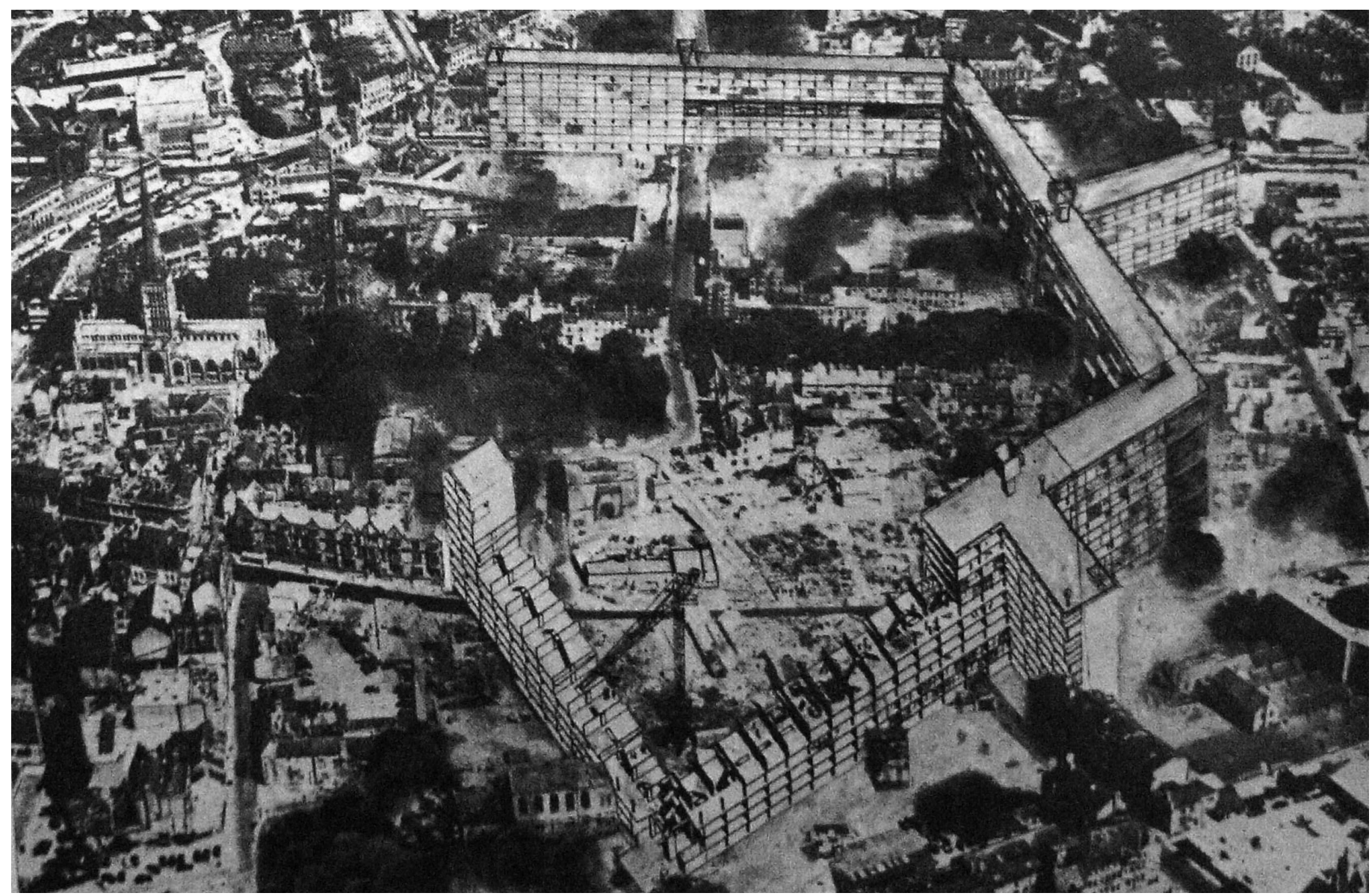


sier para la ville Radieuse y muchas de sus propuestas urbanas, sino que permanecen allí, caracterizando el paisaje como parte indisoluble del mismo, como un terreno expectante para la "espontaneidad" ${ }^{11}$ urbana, pero siempre ajeno a una sustitución masiva y general que lo aleje demasiado rápido de sí mismo borrando su memoria.

\section{Reutilización, movilidad, cambio e indeterminación: nuevos conceptos para una nueva sociedad}

Gran parte de estas reflexiones propositivas de nuevas formas de ocupar el territorio están presentes en The Potteries Thinkbelt, aunque no son los únicos elementos novedosos que Price introduce en este proyecto teórico, donde reúne muchas de las ideas en las que ha estado investigando durante años y con las que se anticipa en décadas a temas que hoy día permanecen aún vigentes, planteando cuestiones de reutilización, movilidad, impermanencia o indeterminación, ${ }^{12}$ que son parte del debate arquitectónico actual y para los que la arquitectura aún sigue buscando respuestas. Este proyecto no recoge una visión utópica de una nueva sociedad mecanicista, ni busca imponer un nuevo mundo, sino que valora lo que existe a su alrededor, con sus bondades y defectos, sin nostalgia, pero sin rechazo. Propone, tras el análisis de la realidad, un cambio para solucionar los problemas existentes en el lugar, tanto los de índole social y económico motivados por la falta de puestos de trabajo por la decadencia de la industria, como los territoriales asociados a un paisaje devastado por los años de explotación de las alfarerías, donde gran parte de la vegetación ha desaparecido, siendo sustituida por edificaciones e infraestructuras que a su vez han quedado ruinosas y obsoletas. Para ello, en PTb se investigan toda una serie de valores que son nuevos y propios, producidos de forma autónoma para esa coyuntura, no conformándose con repetir o modificar fórmulas de otras épocas ya ensayadas y fracasadas, sino avanzando en la capacidad propositiva de la arquitectura a través de nuevos métodos y modelos.

Uno de los principales parámetros introducidos por Price en este proyecto, y en general en la mayoría de sus propuestas arquitectónicas, es el tiempo como material de trabajo de la arquitectura. Los edificios y las infraestructuras no se conciben como un resultado final en un momento determinado, sino que son parte de un proceso que se inicia con la necesidad de su construcción y de los que el proyecto arquitectónico o la construcción y puesta en uso por parte de los usuarios son una fase más, no el fin. En este concepto de work-in-progress de la arquitectura es fundamental entender que los lugares tienen una vida, de la que los edificios que se construyen van a formar parte en un momento determinado, y que una vez insertos en ese lugar también van a sufrir transformaciones; envejecen, necesitan de renovaciones y cambios, pero no todas suceden a la vez, ni de la misma forma, así que parte de ellos pueden seguir teniendo una vida útil, mientras otras no. En la propuesta presentada por Price se hace visible que no es necesario destruir o demoler todo lo existente para implantar algo nuevo, sino que podemos aprovechar las partes que aún son útiles y asociarles otras nuevas, formando un nuevo conjunto que vuelva a ser operativo. Por eso, en el entendimiento de los desequilibrios medioambientales que la sociedad industrial ha dejado en herencia y en su reaprovechamiento está para Price gran parte de la contribución que pueden hacer los arquitectos a la sociedad:
11 Como "espontaneidad" urbana se entiende la aportación no profesional a la textura visual urbana, hecho que había sido discutido en la edición de 1951 de los CIAM y destacado por movimientos como el Pop art, culminando con la exposición de Bernard Rudofsky en el MOMA de Nueva York (1964) denominada "Arquitectura sin arquitectos" (Rudofsky, 1973, p. 1).

12 "Entenderíamos por 'indeterminación' un cierto estado de suspensión de la significación precisa del objeto, producto del replanteamiento de los límites en que este se inscribe [...]. Nos será útil aquí recordar el origen etimológico de la palabra indeterminación. Determinare significa 'limitar', 'Poner límites'. De significa 'desde' y terminare significa 'limitar' (derivado de terminus: 'límite, frontera'. Por tanto, la indeterminación estaría relacionada con aquello que no tiene los límites acotados, definidos, especificados" (Conde, 2000, pp. 59-61). 
Figuras 5 y 6. Esquema de comunicaciones de PTb. Cedric Price, 1966, y Esquema de las áreas de transferencia de PTb. Cedric Price, 1966. Fuente: Canadian Center for Architecture: Collection Center Canadian d'Architecture. Cedric Price fonds
Thus the consciously planned and purposely built environment that exploits the potential of unevenness of environmental conditioning is likely to become one of the main contributions that architects and planners can make to society (Price, 1966, pp. 83-97).

La nueva ocupación territorial que nos propone Price para este lugar semiabandonado es singular, ya que en la puesta en valor de lo existente decide reutilizar las antiguas infraestructuras ferroviarias en desuso, que se convierten en el soporte de la nueva universidad, introduciendo otro de los conceptos innovadores de la propuesta: la movilidad. El campus "se construirá alrededor de una red de carreteras y railes” (Price, 1966, p. 17), que sirven tanto para la comunicación interna del extenso territorio que se propone transformar como de este con el exterior. La facilidad en las comunicaciones y la movilidad individual son fundamentales para el desarrollo de la vida en la zona, tanto por las particularidades del lugar, un área de cierta extensión, como de la propuesta, dispersa sobre él, y de las características de la sociedad que la va a habitar, que busca el desplazamiento y el intercambio como forma de vida, de ahí que el proyecto parta de una vinculación inicial a las vías de comunicación preexistentes.

Las vías del tren, uno de los elementos representativos de la primera revolución industrial, que transformó el verde y tranquilo paisaje agrícola inglés en un lugar inhóspito, adquieren gran protagonismo en esta nueva industria de la enseñanza, al recuperarse como elemento de comunicación para facilitar los desplazamientos de los habitantes y usuarios de la zona, y también porque sirven de soporte para proponer una arquitectura móvil, que puede desplazarse por ellas, ubicándose en diferentes lugares según las necesidades de ocupación en diferentes momentos. El trayecto no es solo un lugar de paso, sino un espacio cambiante donde se pueden realizar distintas actividades. La movilidad lleva aparejada funciones, si necesitamos desplazarnos continuamente este tiempo puede ser ocupado, o también a la inversa, el tiempo que ocupamos en distintas actividades lo podemos aprovechar para desplazarnos. Al igual que al introducir el componente tiempo en la arquitectura, con la concepción de una arquitectura móvil, sin un lugar fijo donde posicionarse, Price se aleja de los principios que han regido la arquitectura durante siglos para intentar adaptarse a una sociedad que
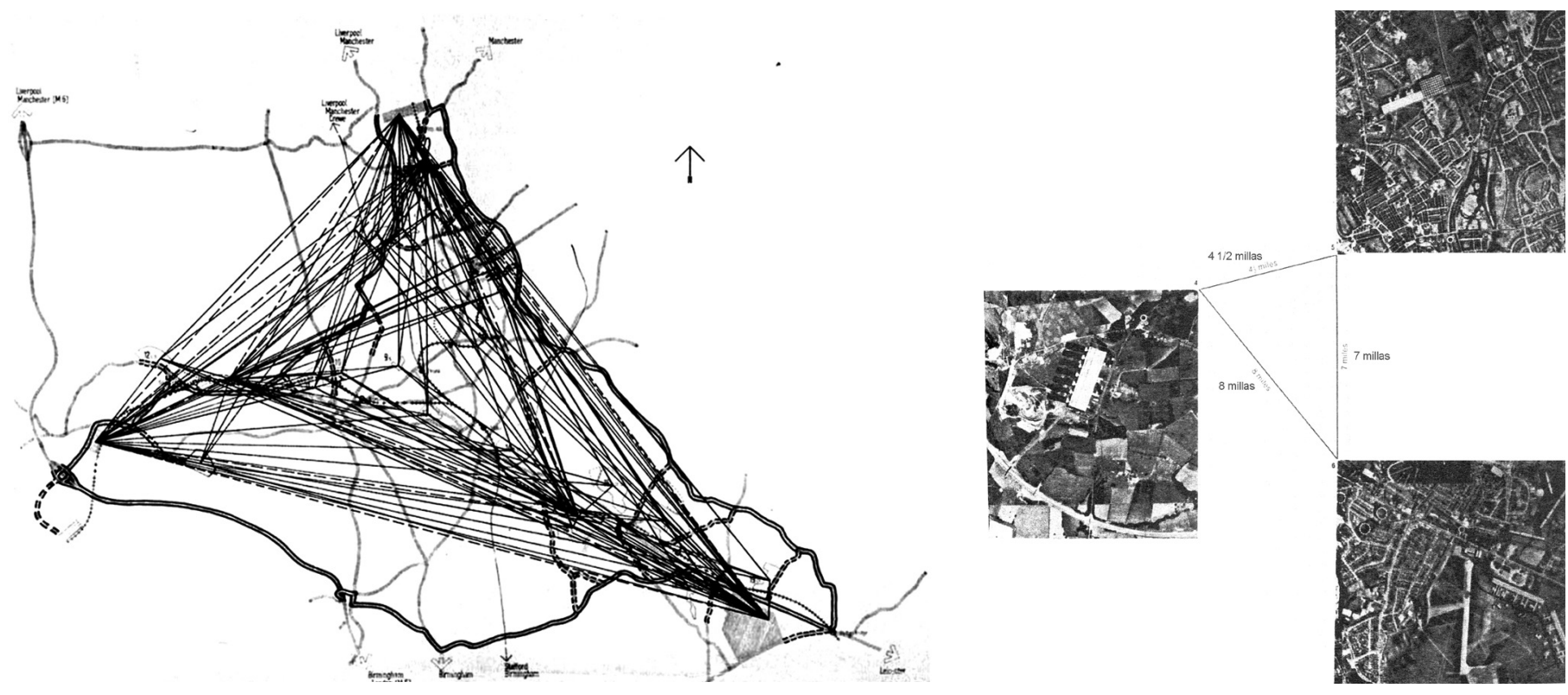
está transformando rápidamente sus modos de vida en base a un desarrollo tecnológico que está creciendo de forma exponencial.

Tras la asunción del trazado del ferrocarril en desuso y las localidades existentes en la zona como base de la intervención, Price define un área de intervención limitada por un triángulo exterior de comunicaciones para evitar las saturaciones de tráfico y los problemas de movilidad que puede producir una propuesta extensiva y dispersa, alejándose de las estructuras radiales que siempre producen embotellamientos en los accesos a su núcleo central. Propone el ferrocarril como red principal para la movilidad interior, reutilizando el extenso trazado existente, incrementándolo en algunas zonas y creando numerosas estaciones interiores con cortos intervalos entre los trayectos. Para favorecer la comunicación interna de esta nueva infraestructura del conocimiento, también propone una nueva red electrónica (no-física) entre los estudiantes y unos lugares denominados almacenes de información, en los cuales los alumnos pueden crear sus propios patrones de estudio, una opción novedosa y premonitoria de las enseñanzas virtuales y los repositorios de la actualidad. Price es capaz de ver a mediados de los años sesenta la importancia que va a tener para las comunicaciones la informática, que se encuentra en un estado muy inicial, la necesidad de recuperar construcciones e infraestructuras o de impulsar el transporte público, preferiblemente por ferrocarril, para salvaguardar un medioambiente cada día más deteriorado y el territorio de un planeta que no es infinito, aplicando unos principios de sostenibilidad prácticamente inexistentes en esa época.

Con esta reutilización del tejido ferroviario para instalar sobre él una "nueva industria" en North Staffordshire, Price pone en cuestión muchos puntos de partida de la disciplina arquitectónica: el lugar entendido como un punto fijo, la permanencia de la arquitectura una vez construida, tanto física como temporalmente, o su capacidad de resistencia al cambio. Alejándose de la forma tradicional del orden preestablecido, poniéndola en crisis, se obliga a buscar nuevas herramientas con las que manipular ese entorno que él ve como cambiante, híbrido y lleno de energía y potencialidades. En esa búsqueda encuentra una propuesta arquitectónica que es el resultado de su capacidad analítica y propositiva. Esta elección y forma de implantación no es casual, sino que es el resultado de una búsqueda de un proyecto de alta indeterminación que huya de:

La legibilidad obvia de la arquitectura, de sus obras cerradas en sí mismas, acabadas el día que termina su construcción, autoreferenciadas y satisfechas por dar cabida a un programa archiconocido y para siempre. En PTb nada es absoluto y cada cosa se disuelve en el resto: la educación en la industria, la industria en el transporte, la vivienda en todas partes [...] (Herreros, 2001, p. 11)

\section{La enseñanza como elemento transformador de la sociedad. El proyecto de Potteries Thinkbelt}

La antigua red ferroviaria abandonada se utiliza como infraestructura básica de la nueva "universidad". A ella se superponen módulos móviles para aulas, laboratorios y unidades residenciales, que también son temporales, porque los ciclos de permanencia de los estudiantes son cortos, de 3 a 5 años, renovándose pasado este periodo de tiempo. Es- 
Figura 7. Planta general de Potteries Thinkbelt. Cedric Price, 1966. Fuente: Hardingham, S. y Rattenbury, K. (ed.) (2007). Potteries Thinkbelt, Cedric Price, Supercrit\# 1. Abingdon: Routledge. tos limitados ciclos de vida pueden permitir la elaboración de prototipos para experimentar con nuevas formas de habitar, y en el caso de resultar óptimos, transferirse al conjunto de la sociedad construyéndose estos tipos ensayados en PTb en otros lugares. Los módulos proyectados pueden desplazarse por toda la región a través del trazado ferroviario que los soporta, o quedarse fijos, abandonándolo en determinados puntos del recorrido, en los apeaderos previstos para ese fin. También pueden combinarse entre ellos o ensamblarse de distintas formas de acuerdo con las necesidades del momento, para conseguir esa máxima variabilidad programática buscada. Así, la propia arquitectura propuesta es un campo de experimentación abierto y continuo, donde la innovación y la transferencia a la sociedad son sus premisas fundamentales.

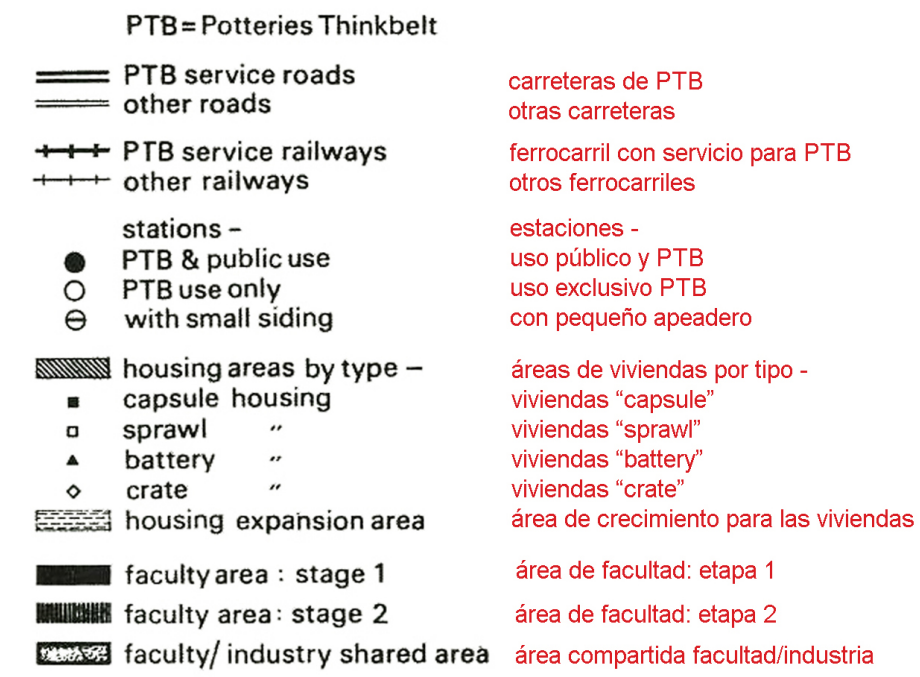

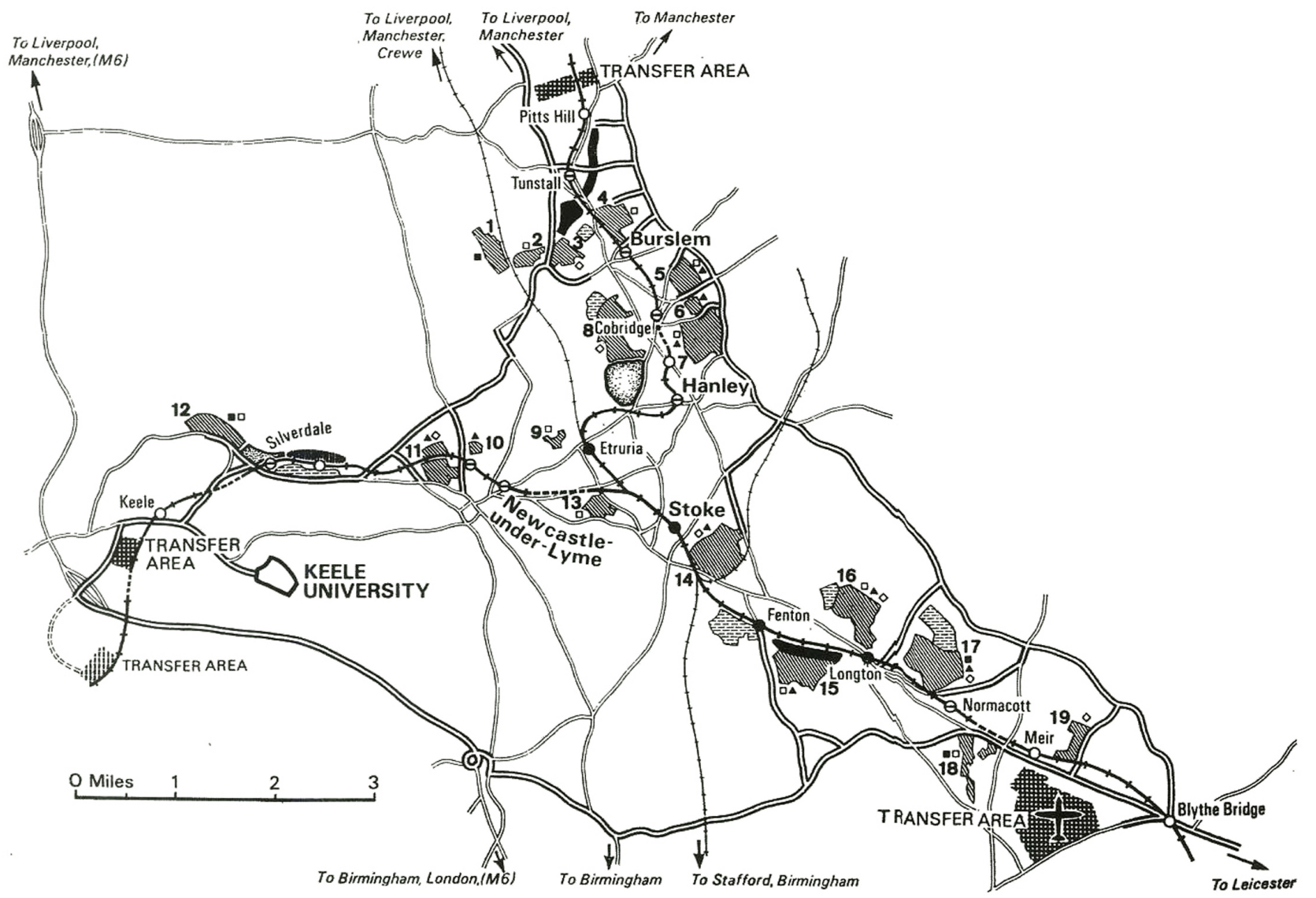


El conjunto del proyecto cuenta con tres puntos fijos principales que se denominan Transfer areas (áreas de transferencia o intercambio) y que sirven para las conexiones del PTb con el exterior, las reconfiguraciones de los módulos y el establecimiento de las edificaciones que necesiten de cierta permanencia. Estas áreas se sitúan en los vértices del triángulo exterior y son: Pitts Hill, que sirve de conexión con Liverpool, Manchester y Sheffield, tanto por carretera como por tren. Allí también se sitúan las plantas experimentales a gran escala y en su proximidad pueden ubicarse áreas flexibles de enseñanza construidas mediante pequeños recintos temporales y alojamientos para los que trabajan allí; Madeley, que enlaza con la M6, una autopista que une Liverpool y Manchester con Birmingham y Londres, en ella se encuentran áreas de trabajo convencionales, que pueden adoptar diversas configuraciones más o menos autónomas, y torres para la inserción de las viviendas crate, un alojamiento temporal para el personal visitante a corto y medio plazo; y Meir, que une Ptb con Leicester a través de la carretera y el ferrocarril, en sus proximidades también hay un aeropuerto, que se conecta con un monorail con el área de intercambio, esto permite un rápido enlace de PTb con cualquier lugar del mundo. Junto a esta Transfer area hay zonas de alojamiento para estudiantes y personal, un área de laboratorio móvil y módulos portátiles para trabajos eventuales. Estas áreas están diseñadas como verdaderos mecanismos con grúas, ascensores, cintas transportadoras y carretillas elevadoras, para proporcionar rápidos intercambios con el "mundo exterior" y hacer el tránsito hacia PTb continuo y fluido, así como para realizar ágiles reconfiguraciones de uso, por lo que, debido a estas necesidades
Figura 8. Área de transferencia de Madeley. Axonometría. Cedric Price, 1966 Fuente: Herreros J. (ed.) (2001) Potteries Thinkbelt (PTb), 1964-66. Caducidad, educación y energía. Arquitecturas silenciosas, 5, Madrid: Ministerio de Fomento, Colegio Oficial de Arquitectos de Madrid.

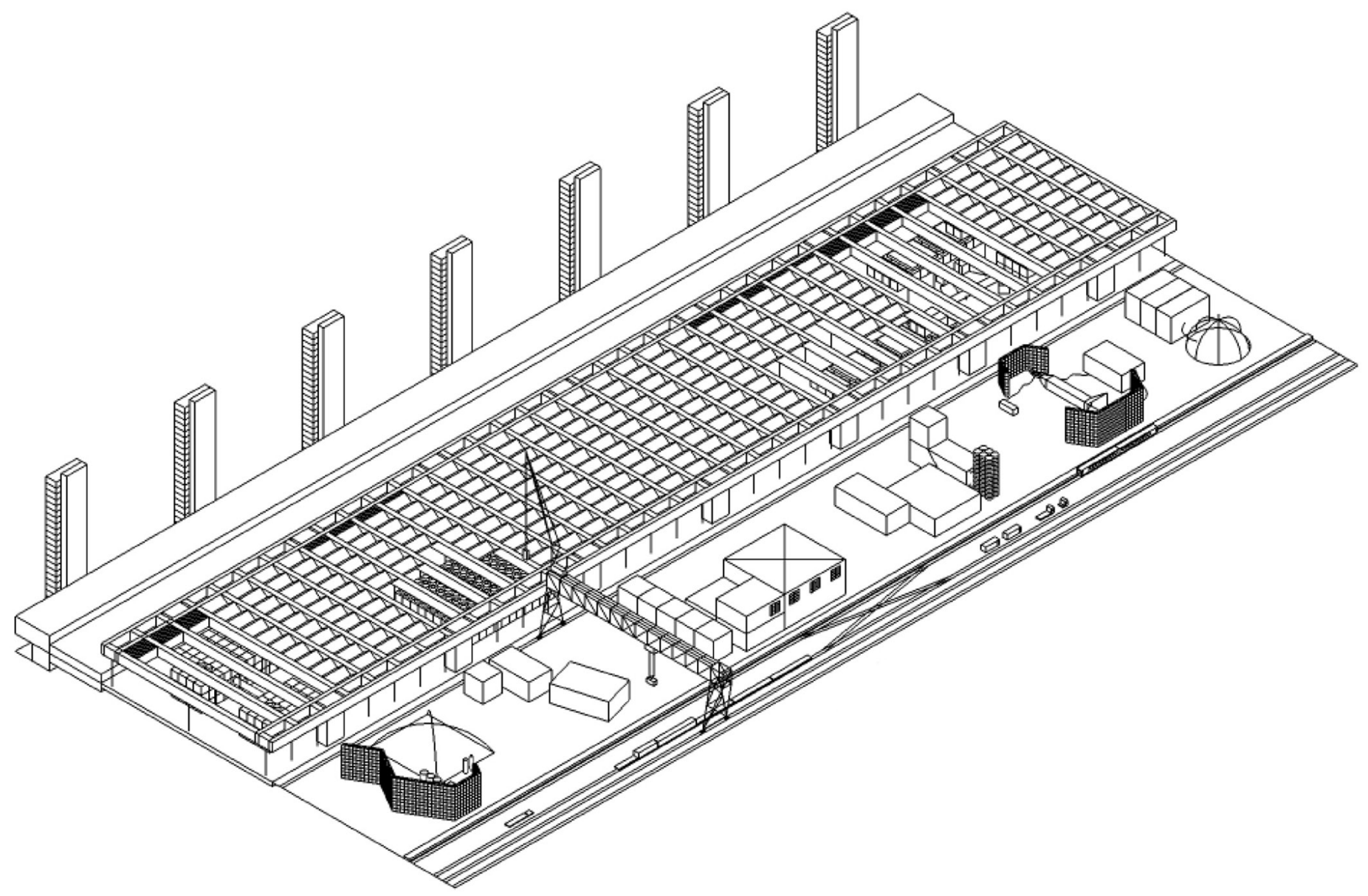




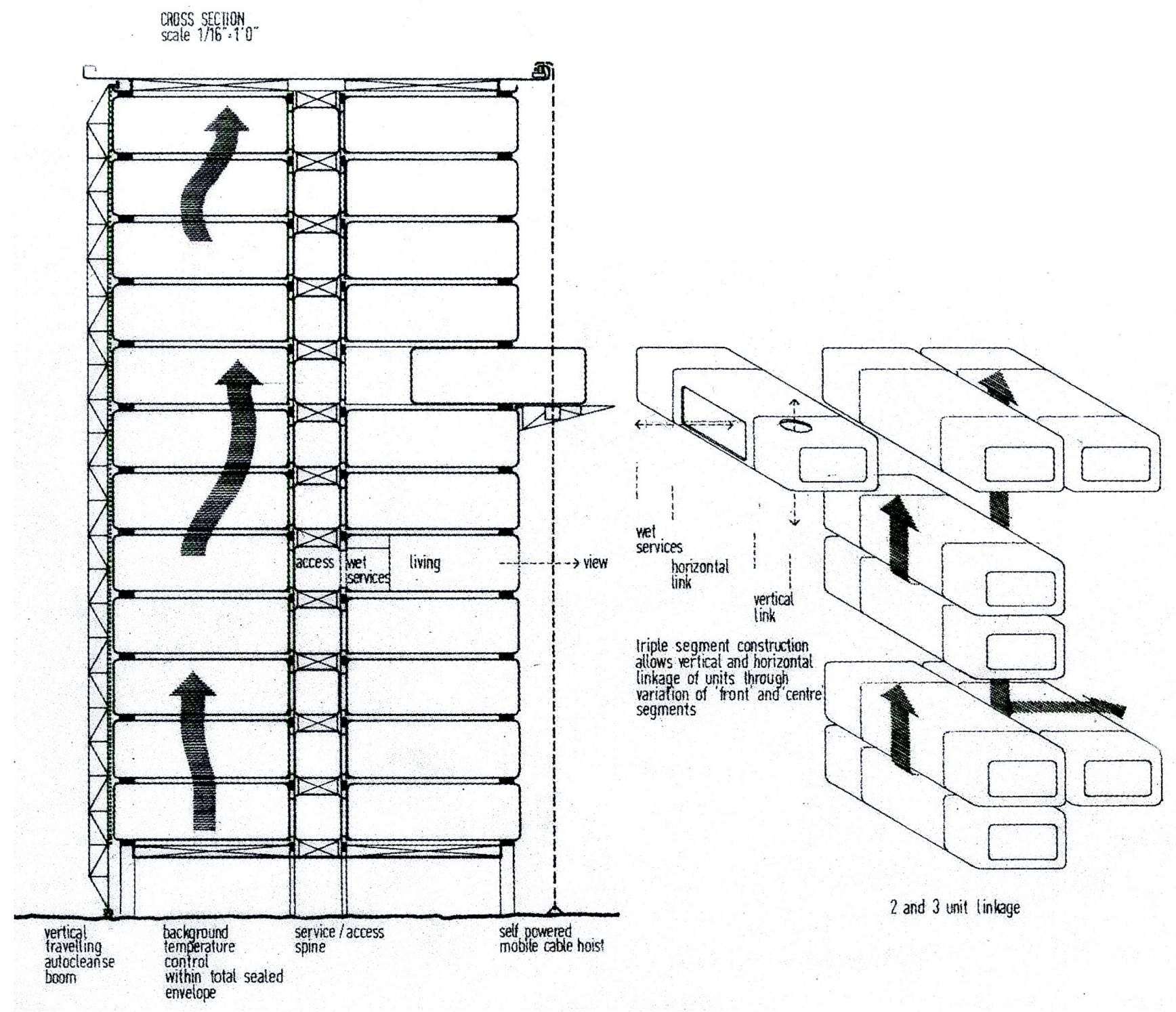

Figura 9. Viviendas crate. Sección transversal. Cedric Price, 1966. Fuente: Canadian Center for Architecture: Collection Center Canadian d'Architecture. Cedric Price fonds.

13 El significado de la palabra crate en inglés es "cajón" o "caja". físicas de movilidad y cambio, asimilan su imagen más a una máquina que a un edificio. En el interior del espacio triangular definido como PTb también se pone en valor la estación existente de Stoke-on-Trent, de la que parte una línea de ferrocarril que tiene comunicación con Londres a través de Stadfford y Birmingham.

La variabilidad programática, otro de los nuevos conceptos arquitectónicos investigados por Price en su trayectoria, también implica nociones de cambio e inestabilidad. La arquitectura se debe adaptar a las necesidades de los usuarios, y como estas cada vez cambian más rápido, nuestros edificios deberán estar pensados para poder soportarlas sin grandes intervenciones, deben ser adaptables con un bajo coste y no solo económico, sino también de materias primas o energía. Por ello, tanto para los módulos de aulas como para los de vivienda, se prevén diversos tamaños y configuraciones, según su posible uso o lugar de estacionamiento, que darían lugar a distintas densidades de ocupación. Se definen cuatro tipos de vivienda que estarían repartidos por todo el área: crate, sprawl, battery y capsule, los nombres también son inventados por Price, lo que las personaliza y singulariza.

Las "viviendas crate" $^{13}$ o cajas de acero se acoplan a una estructura vertical de hormigón de trece niveles, formando "edificios" en altura de gran densidad. Su imagen podríamos verla como una extrapolación 
llevada al límite de la Unidad de Habitación de Le Corbusier, donde las viviendas-caja serían elevadas mecánicamente hasta una posición por cierto espacio de tiempo y pasado este reemplazadas, de una forma casi tan fácil como cuando la mano de Le Corbusier inserta sus módulos de viviendas en la maqueta de su edificio. Para dotarlas de mayor flexibilidad también se plantea un uso de forma individual o enlazando dos o tres unidades, ya sea mediante una asociación horizontal o vertical, lo que proporciona amplias variaciones en el uso de este espacio doméstico. Las viviendas también muestran un interesante grado de sensibilidad hacia el control medioambiental pasivo, ya que el aire que circula alrededor de las unidades les proporciona aislamiento acústico y térmico.

Este tipo de viviendas ideadas por Price, y que nunca llegó a construir, podemos verlas, en cierta medida, ejemplificadas en la torre cápsula de Nakagin construida por Kisho Kurokawa en Tokio entre 19701972 y que en muchos de sus principios las recuerdan. Se trata de dos torres con una macroestructura de hormigón a la que se insertan unas cápsulas de chapa de acero galvanizado, con unas dimensiones mínimas de 2,5 x $4 \mathrm{~m}$, el espacio necesario para la ceremonia del té, equivalente a cuatro tatamis. Las cápsulas son previamente construidas en un taller y equipadas con los últimos adelantos técnicos de la época. Funcionalmente se conciben como viviendas temporales, secundarias (para personas que viven en el área metropolitana de Tokio y deben quedarse en el centro alguna noche), de trabajo u ocio, un híbrido entre el espacio de trabajo - avance de la comunidad digital actual- y el doméstico, y que podrían asociarse a voluntad del inquilino de forma contigua o discontinua. Otro punto importante de conexión con las ideas de Price fue su concepción con un plazo de vida establecido y no como un edificio con aspiraciones de eternidad:

La idea era que las cápsulas se renovarían a los 25 años sustituyéndolas por otras que incorporarían los nuevos avances, en un alarde de obsolescencia programada que recuerda las teorías de Cedric Price y que enlazan con ciertos conceptos de reciclabilidad —Life Clice and Recycle, en palabras del propio KK- que se desarrollarían años más tarde. Quizás por este motivo no se puso mucho empeño en que la construcción de las cápsulas fuera muy duradera, algo muy japonés, por otra parte, o que no se problematizara el hecho de que, a pesar de los esfuerzos por industrializar la construcción, el montaje en taller fuera básicamente artesanal [...]. Incluso el problema que parece decretar el final de la torre - la inaccesibilidad de las instalaciones para permitir su sustitución- no debería ser tenido en cuenta como un fallo del sistema, sino como una expresión de esa vida limitada, según la cual, lo mejor sería sustituir, adaptar, reconfigurar las cápsulas a medida que fuera necesario, sin grandes traumas (Herreros, 2013, pp. 19-20).

Un segundo tipo de viviendas proyectado son las denominadas "viviendas sprawl", ${ }^{14}$ pequeñas edificaciones unifamiliares, aisladas y prefabricadas, de estructura de madera, formadas por la adicción de unidades monofuncionales que permiten la posibilidad de modificación y asociación, creando viviendas con diferentes capacidades para familias de cualquier tamaño, edad o características. Las unidades se apoyan en una bandeja elevada con tres puntos de apoyo regulables que permiten asentarlas en todo tipo de terrenos: irregulares, con fuertes desniveles, o incluso inundables. Price propone principalmente su asentamiento
14 Sprawl es una palabra que se utiliza para definir las áreas de vivienda dispersa, denominándose así a los crecimientos urbanos de baja densidad o suburbanización. 


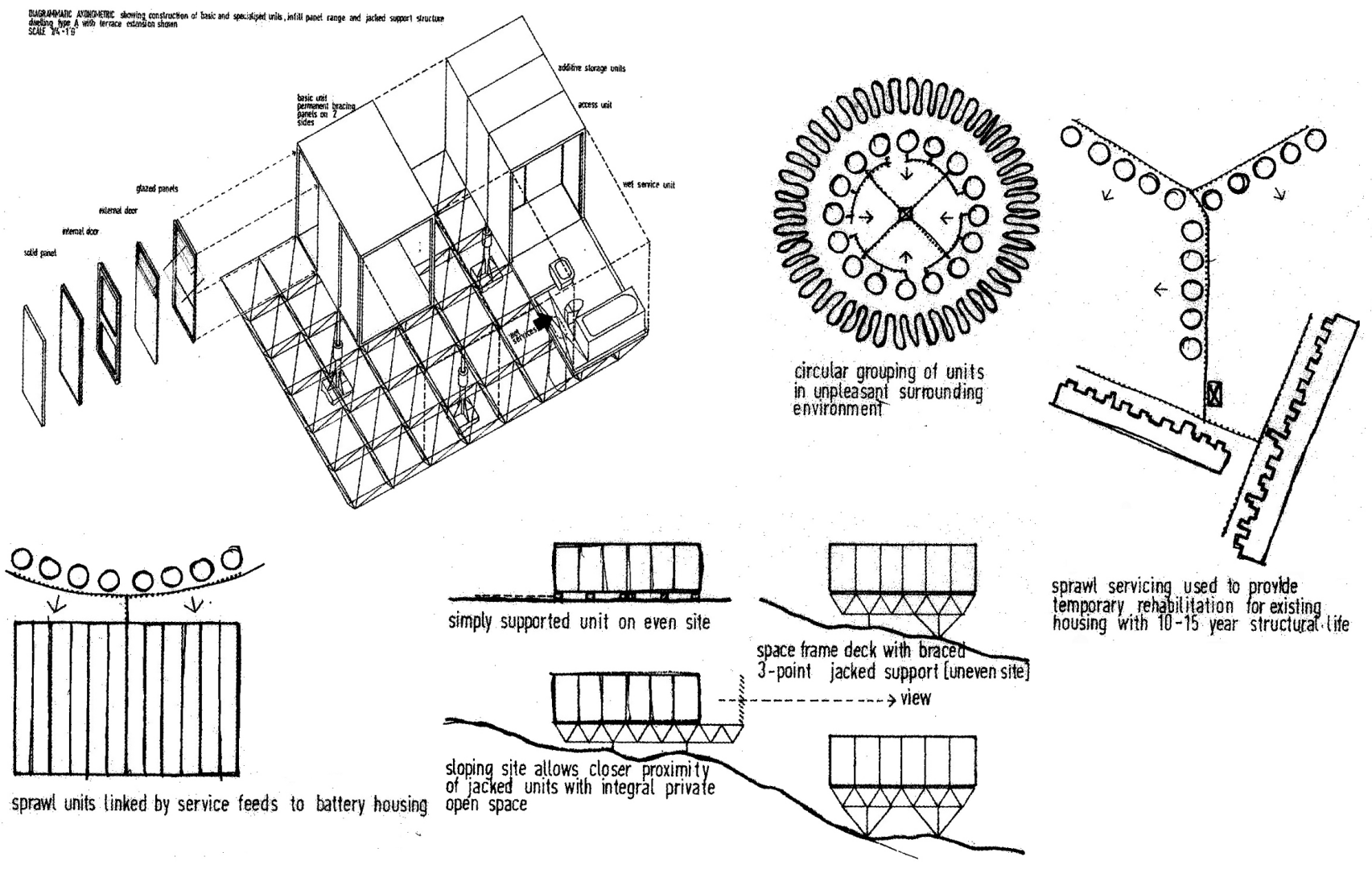

Figura 10. Viviendas sprawl. Axonometría del módulo básico. Cedric Price, 1966. Fuente: Herreros J. (ed.) (2001). Potteries Thinkbelt (PTb), 1964-66. Caducidad, educación y energía. Arquitecturas silenciosas, 5. Madrid: Ministerio de Fomento, Colegio Oficial de Arquitectos de Madrid.
15 Hay dos propuestas fundamentales que ejemplifican las ideas del desurbanismo soviético, el concurso de la ciudad de Magnitogorsk del colectivo Strojkom y el de Moscú verde de Ginzburg y Barsch, ambos publicados en la revista Sovremennaia Arhitektura $n^{\circ} 1$-2, en 1930, en los que se recoge de forma cuantificada y aplicada a lugares reales las ideas fundamentales de este movimiento que parte de un rechazo total del asentamiento humano tradicional mediante concentraciones discontinuas y busca una ocupación territorial continua y homogénea en todo el territorio de la URSS que anule las diferencias entre ciudad y campo (Alarcón y Montero-Fernández, 2012, p. 48). mediante agrupaciones con un esquema lineal, aunque también define algunas asociaciones circulares, para los casos en los que se desee aislarse del paisaje circundante, y siempre con una serie de servicios comunes compartidos que le dan sentido a la agrupación como son la calefacción central, la distribución de electricidad, de agua potable o la depuración de aguas residuales. Esta dotación de servicios comunes de las viviendas sprawl son también utilizados para mejorar los estándares de las viviendas que ya existían en las zonas donde se implantan, buscando en todo momento transformar positivamente la calidad de vida de los habitantes de North Staffordshire. Estas pequeñas viviendas modulares, crecederas, móviles y elevadas, nos recuerdan a las mínimas unidades proyectadas por los desurbanistas soviéticos para los concursos de Magnitogorsk y Moscú Verde, ${ }^{15}$ como una evolución de las mismas, en las que se desarrollan las asociaciones para grupos de personas, así como una ubicación más dispersa en distintos lugares del paisaje, donde comparten su espacio con otros tipos de vivienda, ofreciendo una pluralidad de situaciones para el habitar que muestra la complejidad de la sociedad posindustrial para la que se proyectan.

El tercer tipo definido son las "viviendas-batería", otro tipo de vivienda colectiva que en vez de desarrollarse en altura lo hace horizontalmente, a través de la distribución de módulos dentro de un gran sándwich estructural y de servicios comunes, formado por una superestructura inferior que sirve de suelo a las viviendas, elevada de la cota del terreno, y otra superior para la cubierta. Dentro de esta gran planta libre se lotean las viviendas con una construcción que permite su continua remodelación o transformación. Los dibujos de Price también nos muestran diferentes posibilidades de uso en los elementos estructurales para alcanzar la máxima variabilidad programática buscada. La gran cubierta común resultante se puede utilizar para actividades de recreo al aire libre, como aparcamiento, o no ser accesible. Según ve- 
mos dibujado los vehículos también pueden estacionarse en la estructura inferior del sándwich, o bajo esta, debido a que las viviendas se apoyan, al igual que las sprawl, sobre soportes regulables elevados que permiten situarlas en todo tipo de terrenos irregulares, característicos de este paisaje posindustrial donde abundan las canteras abandonadas.

El último tipo de vivienda definido por Price son las "viviendas capsule", ${ }^{16}$ pequeñas cabinas a modo de vagón de tren o caravana, ${ }^{17}$ que llegarían construidas desde fábrica con estructura metálica y paneles de fibra de vidrio provistos de vidrios transparentes y traslucidos y totalmente equipadas, con muebles plegables y reconvertibles que permiten el solapamiento de las funciones y una gran economía en el uso del espacio. Tienen capacidad para una persona, pero podrían dar cabida a un segundo ocupante por cortos períodos de tiempo. Son concebi-

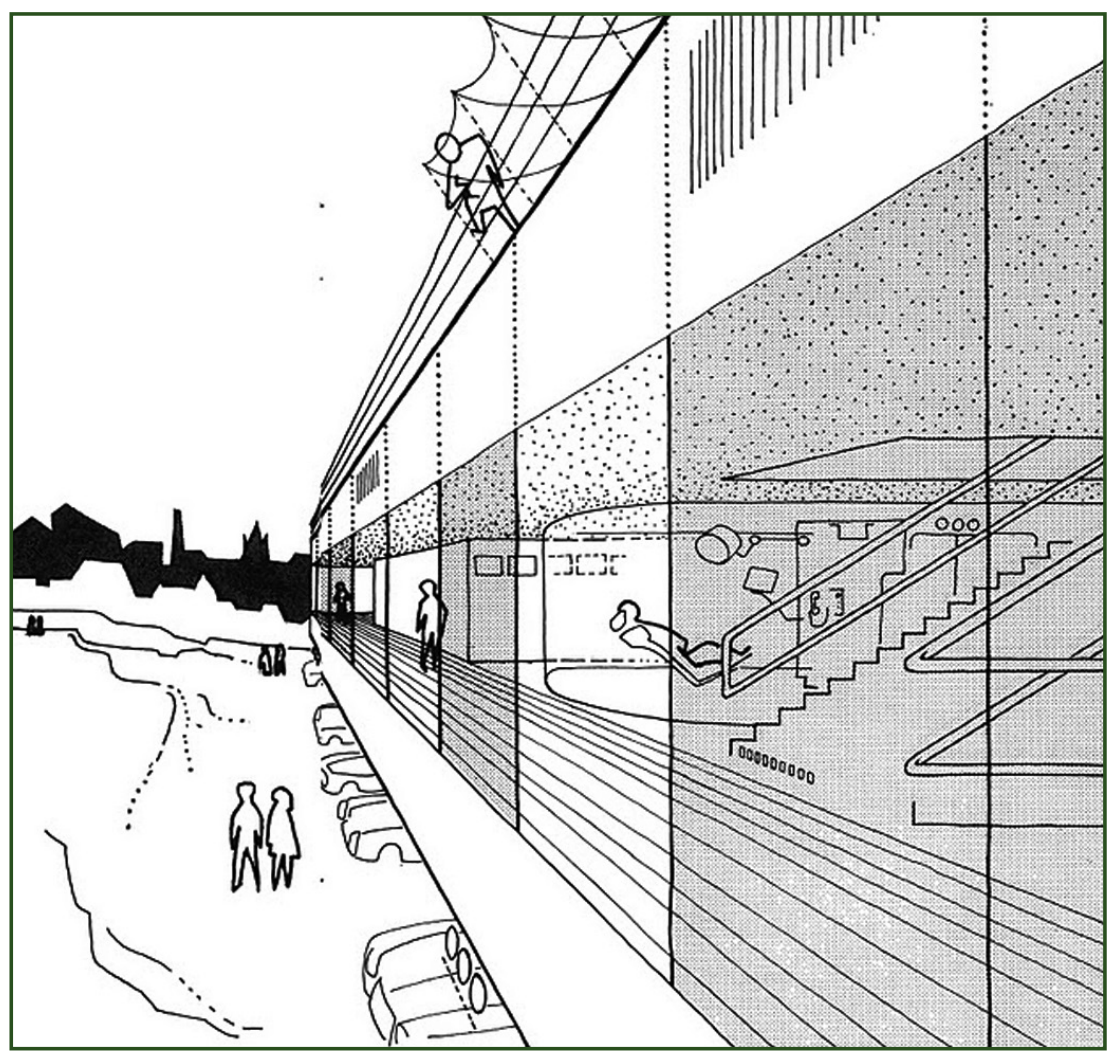
das para alojamientos temporales, ya sea mientras se espera el acceso a otro tipo de vivienda más estable o por puntas de ocupación de la zona. Las unidades se sitúan sobre soportes elevados en lugares agradables y/o con buenas vistas, las posiciones en hilera permiten el control de la privacidad sin pérdida de las vistas. Los diferentes tipos de vivienda se encuentran inicialmente distribuidos en 19 áreas situadas en las proximidades de las poblaciones existentes o de los apeaderos de las líneas férreas. En cada zona Price propone la implantación de uno o varios tipos de vivienda y se ofrece siempre la posibilidad de su transformación o desplazamiento a otras áreas del conjunto.

Las "facultades" o equipamientos para el aprendizaje se sitúan dentro del sistema interno del ferrocarril, en vías activas o muertas y su configuración también varía según las necesidades de cada centro. Los núcleos principales de actividad se vinculan a las áreas de transferencia para facilitar las reconfiguraciones, y también a las zonas donde existen industrias en uso, para fomentar el intercambio entre la enseñanza y sus aplicaciones prácticas. Inicialmente se proponen cinco tipos de módulos o unidades para su combinación, que son: seminarios, constituidos por vagones que pueden utilizarse como parte del servicio normal del tren o por separado, con paradas de duración programada en las estaciones de PTb, también pueden estar estacionados en una vía muerta de forma individual por facultad, ofreciendo oportunidades para la enseñanza teórica programada y los debates informales; cubículos de autoaprendizaje, son módulos previstos para utilizarse de forma autónoma por los alumnos junto con circuitos cerrados de televisión o de información, incorporando las nuevas tecnologías de comunicación a la enseñanza; almacenes de información y equipamiento, son módulos a los que no define ninguna característica especial, pero que aparecen vinculados a las unidades desplegables hinchables, que son elementos que al requerir una anchura mayor que las que permiten las vías del tren se proyectan plegables, de modo que se comprimen para
Figura 11. Viviendas batería. Perspectiva. Cedric Price, 1966. Fuente: Canadian Center for Architecture: Collection Center Canadian d'Architecture. Cedric Price fonds.
16 El significado de capsule en inglés es "compartimento, gabinete, cabina". 17 Estas viviendas están inspiradas, según Stephen Mullin, en la Airstream, un modelo de caravana norteamericana de la década de los treinta, diseñada por Hawley Bowlus, cuyo singular cuerpo de aluminio redondeado llegó a ser un icono del tipo de vida nómada (Hardinghan y Rattenbury, 2007, p. 81). 

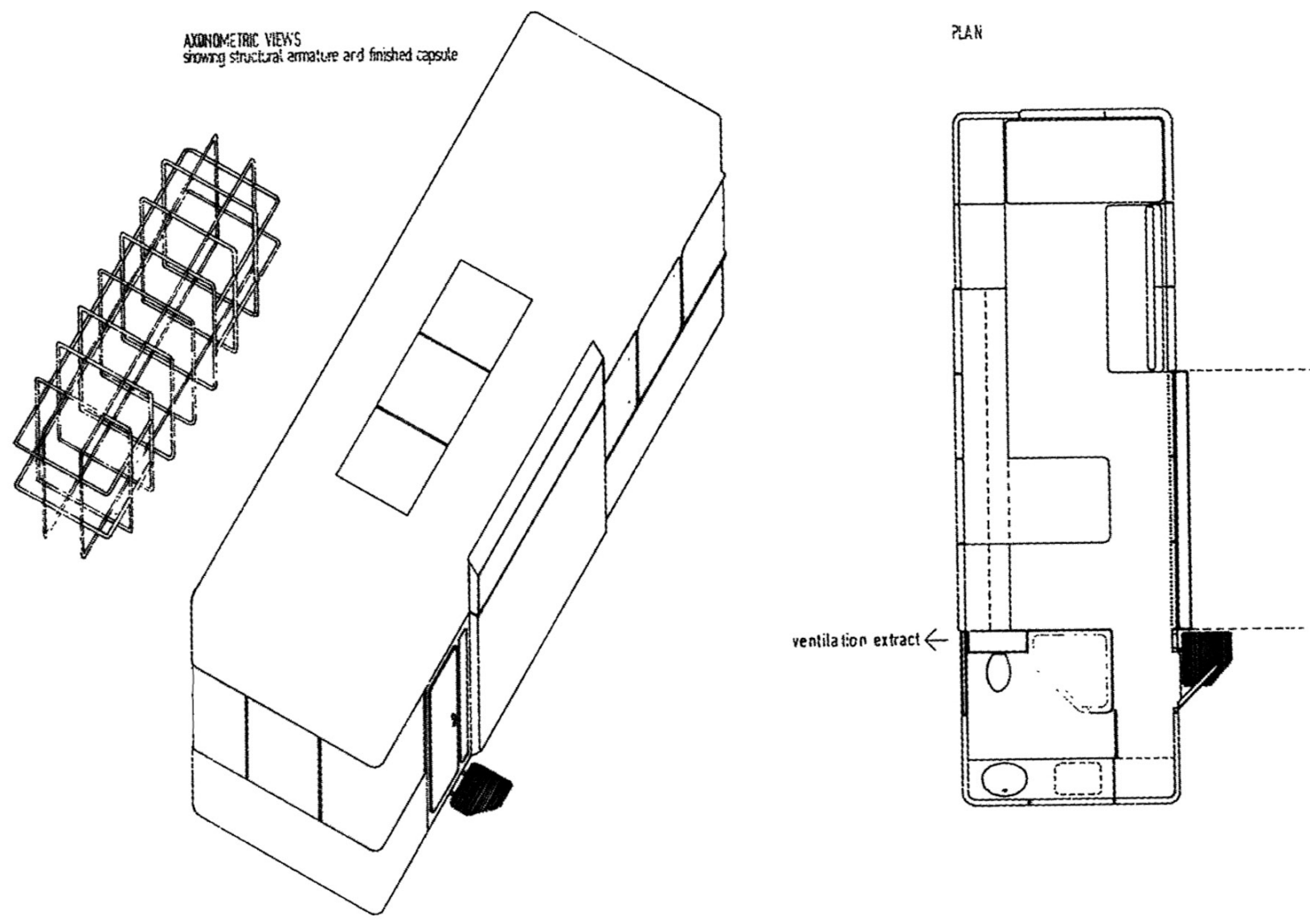

Figura 12. Viviendas capsule. Planta, esquema estructural y axonometría, Cedric Price, 1966. Fuente: Herreros J. (ed.) (2001). Potteries Thinkbelt (PTb), 196466. Caducidad, educación y energía. Arquitecturas silenciosas, 5. Madrid: Ministerio de Fomento, Colegio Oficial de Arquitectos de Madrid.

Figura 13. Esquemas de las unidades de enseñanza asociados al ferrocarril. Cedric Price, 1966. Fuente: Canadian Center for Architecture: Collection Center Canadian d'Architecture. Cedric Price fonds. desplazarse y se expanden una vez posicionados, ofreciendo dos posibles usos, como dos salas de conferencias para unas 30 personas cada una o para demostraciones televisadas; y por último, se definen las unidades de cubierta plegable, cuya función es auxiliar, dando acceso a otras unidades, o como apoyo para unidades especializadas o de control.

En el conjunto del área también se prevé la introducción de equipamientos de carácter cívico-social, porque el incremento previsto de habitantes demanda nuevos espacios para el tiempo libre. Esto, a su vez, producirá una mejoría en las condiciones de vida de la zona. Estos usos lúdicos y de recreo se sitúan próximos a las áreas destinadas a viviendas. Entre ellos encontramos Westport Lake, que será rehabilitado para actividades de recreo, como la navegación y el esquí acuático, permitiendo el acceso desde el área de Tunstall/Burstem y expandiendo la influen-
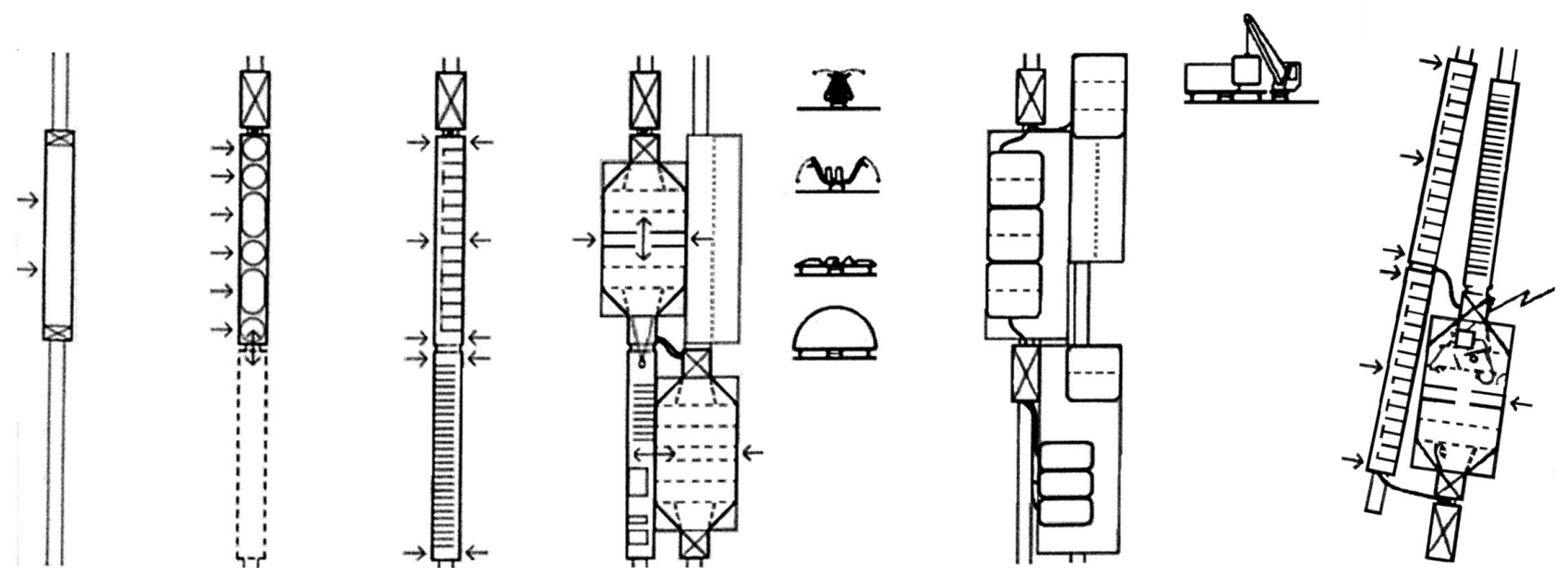
cia de la propuesta más allá de Broadwell Woods. Igualmente, se plantea la construcción de recintos especializados de pequeña escala, como pistas de squash, en el área de los bloques de las viviendas batería. Estas actuaciones buscan funcionar como germen de nuevas actividades, ya que cuando la nueva infraestructura universitaria esté funcionando en su totalidad aparecerán nuevas demandas que pueden ser satisfechas desde la actividad empresarial privada o los organismos locales, reactivando la economía de la zona.

\section{Conclusiones}

Price se anticipa con PTb en décadas, proponiendo una arquitectura de gran variabilidad programática, capaz de transformarse fácilmente en el tiempo y convertirse en un elemento distinto según sean los momentos y situaciones, condiciones que la acercan más a las características de la tecnología informática, muy rudimentaria en esta época, que a las de la industria, aproximándose más al concepto de lo cibernético que a los modelos maquinistas utilizados como referentes por Le Corbusier y los arquitectos del Movimiento Moderno. El proyecto supera esa primera condición de la industrialización para situarse en un momento posterior en el cual los medios de comunicación y las transacciones de la información han superado a lo puramente mecánico. Existe un entendimiento del momento y el lugar que trasciende el presente para situarse en un incierto más allá. Price es consciente de que el arquitecto no tiene por qué conocer el futuro que le espera a una edificación, de cuál va a ser su devenir (Mathews, 2001, p. 27), y eso se refleja en una arquitectura que busca lo transitorio y lo temporal, huyendo de la permanencia y lo establecido, de la posibilidad de crear un orden definitivo y total, asumiendo de forma clara la indeterminación de lo proyectado. Conceptos como obsolescencia desaparecen frente a la posibilidad de cambio, algo posible en esta arquitectura que posee gran capacidad de transformación y que tampoco espera ser eterna, al ser proyectada para una expectativa de vida de 20 años.

Asimismo, la construcción de PTb supondría una mejora social, cultural y económica para la zona, al ponerle a la población local al alcance el conocimiento y los eventos que en ella se produjeran. La propuesta al hibridarse con lo existente permite un enriquecimiento de ambas partes, un mestizaje intelectual, en el que los nuevos habitantes de la zona aportarían vida al lugar, conocimiento y riqueza, y a su vez aprenderían de las tradiciones y la historia del territorio. Las investigaciones e innovaciones tecnológicas desarrolladas en este expandido campus universitario también se busca que sirvan para relanzar la industria local en retroceso, que se beneficiaría de ellas, y atraer a otras nuevas que a su vez se alimentarían de estos avances. El tejido industrial existente se utiliza como una amplia área docente y de trabajo, coordinado entre la industria y el PTb, como se propone en Hanley, donde existen importantes fábricas de hierro y acero, y en Shelton y Silverdale, donde se encuentra una mina de carbón.

Esta vinculación universidad-sociedad no se plantea como una circunstancia puntual, sino como un nuevo sistema de la enseñanza superior. De hecho, Price considera que PTb es solo un ejemplo en un área concreta, pero no una respuesta exclusiva, sino que siguiendo este "gran experimento" se podrían hacer otras actuaciones similares en otras partes del Reino Unido y a través de ellas convertir la enseñanza 

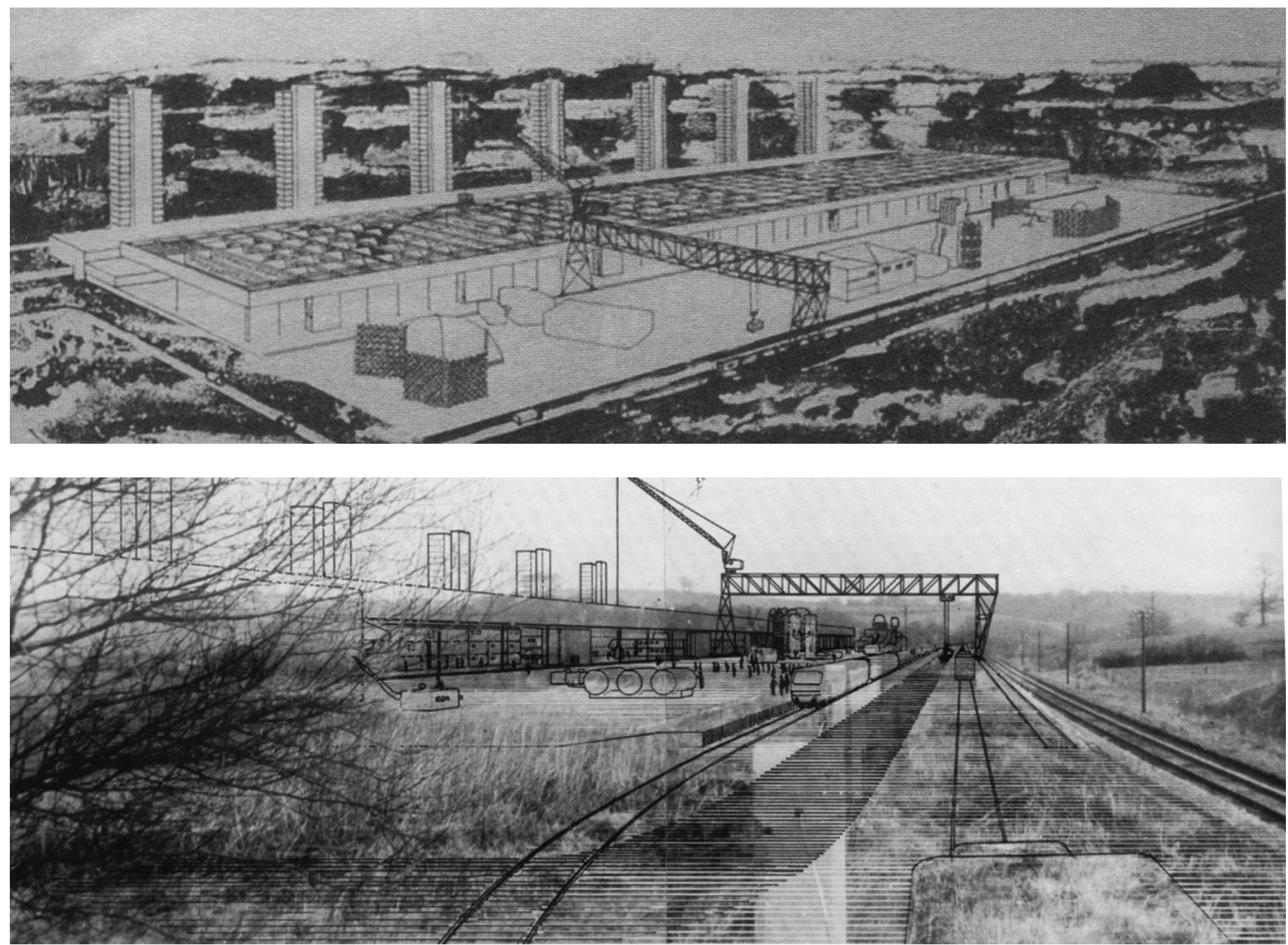

Figuras 14 y 15. Collages del área de transferencia de Madeley, Potteries Thinkbelt. Cedric Price, 1966. Fuente: Canadian Center for Architecture: Collection Center Canadian d'Architecture. Cedric Price fonds. en la mayor industria del país, con la que podrían ganar dinero y cerebros (Hardingham y Rattenbury, 2007, p. 20), así como en el elemento generador de las nuevas ocupaciones territoriales. Inicialmente, la defensa, las fuentes de energía o materias primas y el comercio han sido elementos generadores para las ciudades, que deben su fundación a alguno de estos parámetros. En cambio, este proyecto supone que la educación y la necesidad de intercambio de información pueden tener una fuerza generadora similar: las ciudades actuales pueden ser construidas o transformadas por el aprendizaje.

Este proyecto de una nueva industria educacional avanzada no fue ejecutado, pero la innovadora interpretación de la realidad en la que se desenvuelve le lleva a realizar una propuesta que tiene la capacidad de sobrevivir a su época, permanecer vigente hoy día y promover en nuestra mente el desarrollo de nuevas ideas de ocupación del territorio, de generar nuevos hábitats o de desarrollar nuevos sistemas de aprendizaje, llevándonos a imaginar nuevos lugares donde sus condiciones intrínsecas se revalorizaran con la introducción de una nueva estructura educativa-productiva, una industria que podría ser la educación avanzada entendida como un $\mathrm{I}+\mathrm{D}$, que sirviera de apoyo cualquier estructura productiva prexistente, lo que llevará de forma implícita la permanencia de lo existente mediante una convivencia simbiótica de ambas, en vez de su destrucción. Una situación opuesta a la del planeamiento urbano actual, en el que de forma recurrente se transforma el territorio mediante procesos de sustitución global, eliminando las huellas de lo que había para introducir desde cero el nuevo uso ideado. 


\section{Referencias}

Alarcón González, L. y Montero-Fernández, F.J. (2012). Aprendiendo de los concursos. La investigación en arquitectura, Proyecto, progreso y arquitectura, 7, 38-53.

Canadian Center for Architecture (2013). Collection Center Canadian d'Architecture. Cedric Price fonds. Recuperado el 9 de mayo de 2013 de: http:/ / cel.cca.qc.ca.

Castell, M. (1974). La Cuestión Urbana. Madrid: Editorial Siglo XXI.

Conde, Yago (2000). Arquitectura de la indeterminación. Barcelona: Actar.

Hardinghan, S. y Rattenbury, K. (eds.) (2007). Potteries Thinkbelt, Cedric Price, Supercrit\#1. Abingdon: Routledge.

Herreros, J. (2001). Cedric Price. Cuarenta años de heterodoxia propositiva. En Herreros, J. (eds.), Potteries Thinkbelt (PTb), 1964-66. Caducidad, educación y energía. Arquitecturas silenciosas, 5. Madrid: Ministerio de Fomento, Colegio Oficial de Arquitectos de Madrid, pp. 6-17.
Herreros, J. y Yamazaki, R. (dir.) (2013). Kisho Kurokawa. La torre cápsula de Nakagin, Bacelona: Fundación Caja de Arquitectos.

Mathews, S. (2001). Potteries Thinkbelt (PTb), 196466: una arquitectura de incertidumbre calculada. En Herreros J. (eds.), Potteries Thinkbelt (PTb), 196466. Caducidad, educación y energía. Arquitecturas silenciosas, 5. Madrid: Ministerio de Fomento, Colegio Oficial de Arquitectos de Madrid, pp. 18-31.

Price, C. (1966). PTb. Potteries Thinkbelt. A plan for an advanced educational industry in North Stafforshire, Architectural design, 10, 483-497.

- (1966). The Potteries Thinkbelt, New Society, 192, 14-17.

Rudofsky, B. (1973). Arquitectura sin arquitectos. Buenos Aires: Editorial Universitaria de Buenos Aires.

Smithson, R. (2006.) Un recorrido por los monumentos de Passaic, Nueva Jersey. Barcelona: Gustavo Gili.

Alarcón González, L. y Montero-Fernández, F. (2017). Nuevas interacciones entre universidad, sociedad y territorio a través de una propuesta para una industria educacional avanzada. The Potteries Thinkbelt. Hábitat y Sociedad, 10, 203-222.

<http://dx.doi.org/10.12795/HabitatySociedad.2017.i10.12>

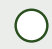




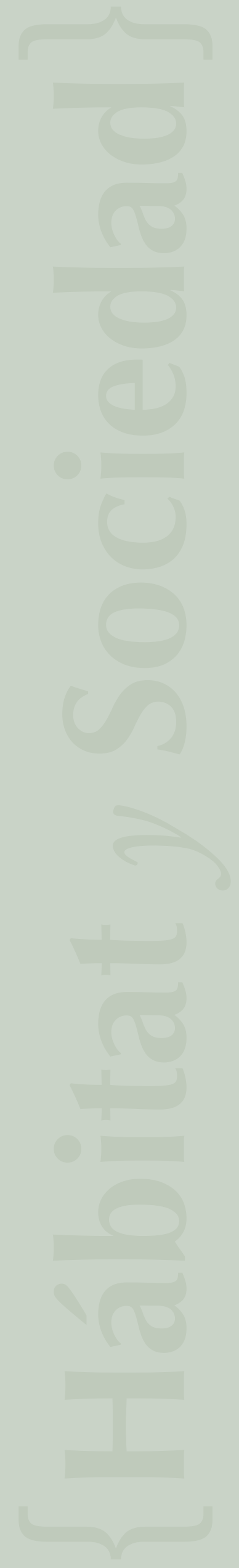

